\title{
Theory of computation: P systems. Articles dedicated to Kamala Krithivasan on her 70th birthday, Issue-I
}

\author{
Kalpana Mahalingam ${ }^{1} \cdot$ Raghavan Rama $^{1}$
}

Published online: 17 September 2018

(C) Indian Institute of Technology Madras 2018

Prof. Kamala Krithivasan has turned years to Platinum celebrating her 70th birthday and what could be a more befitting tribute than the dedication of two special issues in appreciation of her scientific contributions and her role as a teaching faculty. As a matter of fact, both the special issues dedicated to her, are contributions invited by the guest editors. The first issue concentrates on aspects of computing $\mathrm{P}$ systems while the second one focuses on other computing models.

$\mathrm{P}$ systems is a parallel distributed computing model that has attracted several researchers in the recent years. $P$ colonies, tissue-like $\mathrm{P}$ systems, Contextual array $\mathrm{P}$ systems, $\mathrm{P}$ systems with active membranes, $\mathrm{P}$ systems with controlled computations are some variants that are widely studied. This issue on P Systems brings out three articles on the modeling aspects and three articles on computational complexity aspects.

A brief walk down the academic lane of Kamala Krithivasan would be of value to practitioners in areas such as Formal Language and Automata, Molecular Computing, Discrete Tomography, Design and Analysis of Algorithms and Graph Grammars and L systems.

Kalpana Mahalingam

kmahalingam@iitm.ac.in

1 Department of Mathematics, Indian Institute of Technology, Chennai, India

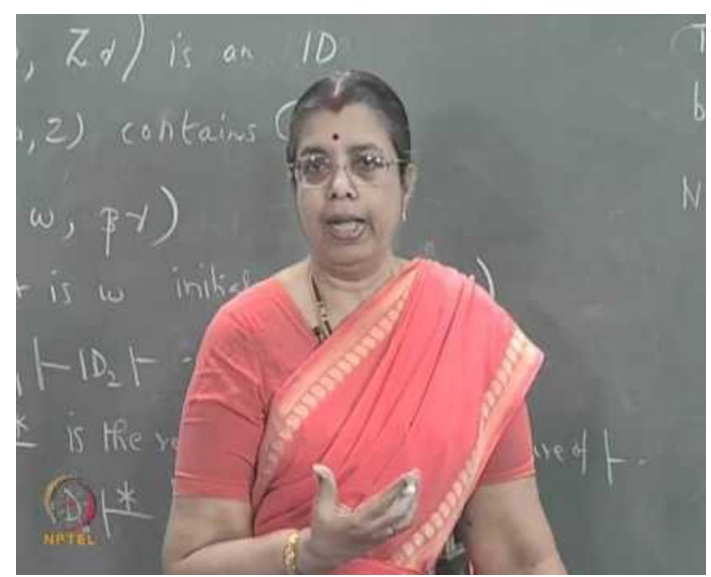

Prof. Kamala Krithivasan was born on July 6, 1948 in Tamilnadu, India. She studied Mathematics at the Madras Christian College, Chennai. She took off with a doctoral degree in Mathematics with specialization in Theoretical Computer Science under the guidance of Prof. Rani Siromoney. From then on, she never stopped expanding her research interests handling any related area delving into infinite details, striving hard to explore deeper scopes for analysis and research. She has to her credit a large number of Journal publications and also guided many project/research students. She has also held responsible memberposts in reputed institutions. She has been member of board of studies in many universities for specified periods, and was a member of the editorial board of our Institute Journal "Journal of Mathematical and Physical Sciences" and many more could be enlisted thus. Kamala Krithivasan is presently active as, a Member of the Board of Directors for IIITM-Kerala, Member of the special committee for school of Computer and System Sciences, Jawaharlal Nehru University, New Delhi. 
As a professor within the campus, she has been most sought after by the students for she has been a wonderful teacher and guide, always accessible to the students' need; though she was prudent and conservative academically. Among her colleagues she has always enjoyed an excellent rapport either coordinating a task or volunteering her service in each and every academic programme taking place in the departments.

To precisely sum up her command and competence over the subject she has nurtured and excelled all through her academic journey thus far, a mention has to be made about the Book that she has co-authored. This would for sure steal the spotlight of all her experience and achievements. Besides co-authoring, she has also edited a few books on Formal Languages. The online NPTEL courses on Discrete Mathematics and Automata Theory that she has offered are known for rich content and insightfulness.

The authors of these special issues are reputed co-authors, collaborators or research successors and have been ardent admirers of Prof. Kamala Krithivasan. We immensely thank all the contributors and the reviewers. 